\title{
ANALISIS FAKTOR YANG MEMPENGARUHI PERTUMBUHAN EKONOMI DI KABUPATEN JEMBRANA TAHUN 2008-2017
}

\author{
I Gede Wangga Nugraha Putra ${ }^{1}$, lyus Akhmad Haris ${ }^{1}$, Lulup Endah Tripalupi ${ }^{2}$ \\ Program Studi Pendidikan Ekonomi \\ Universitas Pendidikan Ganesha \\ Singaraja, Indonesia
}

e-mail:\{gungajinugraha@gmail.com, akhmad.haris@undiksha.ac.id, endah.tripalupi@undiksha.ac.id\}@undiksha.ac.id

\begin{abstract}
Abstrak
Penelitian ini bertujuan untuk mengetahui faktor-faktor yang mempengaruhi pertumbuhan ekonomi di Kabupaten Jembrana tahun 2008-2017, dan faktor yang paling dominan mempengaruhi pertumbuhan ekonomi di Kabupaten Jembrana tahun 2008-2017. Penelitian ini merupakan penelitian faktorial yang dilaksanakan di BAPPEDA Kabupaten Jembrana dan BPS Kabupaten Jembrana dengan data berupa Produk Domestik Regional Bruto (PDRB) tahun 2008-2017. Data dikumpulkan dengan metode dokumentasi dan dianalisis dengan analisis faktor melalui Statistical Program Social Scence (SPSS) 16.0 for windows. Hasil penelitian menunjukan bahwa terdapat 7 (tujuh) faktor yang mempengaruhi pertumbuhan ekonomi di Kabupaten Jembrana tahun 2008-2017, yaitu faktor; sumberdaya alam $\left(x_{1}\right)$, akumulasi modal $\left(\mathrm{x}_{2}\right)$, organisasi $\left(\mathrm{x}_{3}\right)$, kemajuan teknologi $\left(\mathrm{x}_{4}\right)$, pembagian kerja dan skala produksi $\left(\mathrm{x}_{5}\right)$, sosial $\left(\mathrm{X}_{6}\right)$, dan politik dan administrative $\left(\mathrm{x}_{7}\right)$. Faktor yang paling dominan mempengaruhi pertumbuhan ekonomi di Kabupaten Jembrana tahun 2008-2017 adalah faktor sumberdaya alam yang memiliki variance explained tertinggi yaitu sebesar $96,649 \%$, artinya bahwa faktor sumberdaya alam mampu menjelaskan pertumbuhan ekonomi di Kabupaten Jembrana tahun 2008-2017 sebesar 96,649\%.
\end{abstract}

Kata kunci:Pertumbuhan ekonomi, Kabupaten Jembrana

\section{Abstract}

This study aims to determine the factors that influence economic growth in Jembrana Regency in 2008-2017, and the most dominant factors affecting economic growth in Jembrana Regency in 2008-2017. This research was a factorial study carried out at the BAPPEDA Jembrana Regency andBPS Jembrana Regency with data in the form of Gross Regional Domestic Product (GRDP) in 2008-2017. Data were collected by the documentation method and analyzed by factor analysis through Statistical Social Scence Program (SPSS) 16.0 for Windows. The results showed that there were 7 (seven) factors that influenced economic growth in Jembrana District in 2008-2017, namely; natural resource $\left(x_{1}\right)$, capital accumulation $\left(\mathrm{x}_{2}\right)$, organizational $\left(\mathrm{x}_{3}\right)$, technological progress $\left(\mathrm{x}_{4}\right)$, labor division and production scale $\left(x_{5}\right)$, social $\left(x_{6}\right)$, and political and administrative $\left(x_{7}\right)$. The most dominant factor influencing economic growth in Jembrana Regency in 2008-2017 was the natural resource factor which had the highest explained variance which was equal to $96,649 \%$, meaning that natural resource factors were able to explain economic growth in Jembrana Regency in 2008-2017 by $96,649 \%$.

Keyword:Economic growth, Jembrana Regency 


\section{PENDAHULUAN}

Pertumbuhan ekonomi adalah peroses perubahan perekonomian suatu negara secara berkesinambungan menuju perkembangan yang lebih baik dalam periode waktu tertentu.Pertumbuhan ekonomi merupakan peroses kenaikan kapasitas produksi suatu perekonomian yang tercermin dari kenaikan pendapatan nasional. Sukirno (2008) mengungkapkan bahwa pertumbuhan ekonomi merupakan perkembangan kegiatan dalam perekomomian yang menyebabkan barang dan jasa yang diproduksi dalam masyarakat bertambah sehingga akan meningkatkan kemakmuran masyarakat.

Menurut Jinghan, M.L. (2012), ada delapan faktor sebagai sumber pertumbuhan ekonomi yaitu; sumberdaya alam, akumulasi modal, organisasi, kemajuan teknologi, pembagian kerja dan skala produksi, faktor sosial, faktor manusia, serta faktor politik dan administratif. Menurut Sukirno (2011), ada empat faktor sebagai sumber dari pertumbuhan ekonomi yaitu; tanah dan kekayaan alam lainnya, jumlah dan mutu dari penduduk dan tenaga kerja, barangbarang modal serta tingkat teknologi dan sistem sosial dan sikap masyarakat. Sumberdaya alam atau tanah mencakup kesuburan tanah, letak dan susunannya, kekayaan hutan, iklim, sumber air, sumber lautan.Kekayaan sumberdaya alam sangat membantu perekonomian suatu daerah apabila didukung oleh penanaman modal dari pihak dalam negeri maupun pihak luar negeri. Sehingga dengan adanya modal, pemerintah daerah dapat menggunakan keahlian sumberdaya manusia untuk mengeksplorasi kekayaan alam yang ada, serta mampu mempergunakan teknologi untuk menghasilkan output yang lebih banyak dengan input yang sama.

Pertumbuhan ekonomi dapat digunakan sebagai salah satu tolak ukur yang dapat dipakai untuk mengetahui adanya pembangunan daerah dari berbagai macam sektor ekonomi yang secara tidak langsung menggambarkan tingkat pertumbuhan ekonomi.Kegiatan ekonomi yang beranekaragam mendorong setiap daerah untuk mengembangkan potensi ekonominya, oleh karena itu pembangunan daerah dilaksanakan secara terpadu dan serasi serta diarahkan agar pembangunan yang berlangsung di setiap daerah benarbenar sesuai dengan prioritas dan potensi daerah.

Salah satu indikator yang penting untuk mengetahui kondisi ekonomi di suatu wilayah atau Provinsi dalam suatu periode tertentu ditunjukkan oleh data Produk DomestikRegional Bruto (PDRB).Produk Domestik Regional Bruto diartikan sebagai berapaproduk yang dihasilkan pada suatu daerah dalam satu periode waktu tertentu.Dari nilai PDRB ini dapat digambarkan sejauh mana kemampuan daerah dalam mengelola atau memanfaatkan sumber daya yang ada.

Kabupaten Jembrana adalah salah satu dari sembilan kabupaten dan kota yang ada di Provinsi Bali dengan luas wilayah mencapai $841,80 \mathrm{Km}^{2}$ atau $14,93 \%$ dari Provinsi Bali, terluas ketiga setelah Kabupaten Buleleng dan Kabupaten Tabanan. Dengan luas daerah yang demikian memiliki potensi yang sangat besar untuk memiliki pertumbuhan ekonomi yang tinggi, khususnya dalam sektor pertanian maupun sektor-sektor lain seperti perkebunan, perikanan, industri maupun perdagangan.tetapi angka pertumbuhan ekonomi di Kabupaten Jembrana masih lebih rendah dibandingkan dengan daerah yang memiliki luas wilayah lebih kecil dengan Kabupaten Jembrana, seperti Kabupaten Karangasem, Kabupaten Gianyar, Kabupaten Badung dan Kabupaten lainnya.

$$
\text { Menurut Kencana Kerja }
$$

Pembangunan Daerah (RKPD) dan data BPS Kabupaten Jembrana, Kabupaten Jembrana berdasarkan indikator distribusi persentase nilai tambah bruto sektoral, terdiri dari sembilan sektor yaitu pertanian, pertambangan dan penggalian, industri pengolahan, listrik, gas dan air bersih, bangunan, perdagangan, hotel dan restoran, pengangkutan dan komunikasi, keuangan, persewaan dan jasa 
p-ISSN : 2599-1418

e-ISSN : 2599-1426

perusahaan, serta jasa-jasa. Pertumbuhan ekonomi suatu daerah ditunjukkan dengan laju pertumbuhan PDRB suatu daerah baik berdasarkan harga konstan maupun dengan harga berlaku.PDRB atas dasar harga berlaku atau dikenal dengan PDRB nominal disusun berdasarkan harga yang berlaku pada periode penghitungan, dan bertujuan untuk melihat struktur perekonomian.Sedangkan PDRB atas dasar haga konstan disusun berdasarkan harga pada tahun dasar dan bertujuan untuk mengukur pertumbuhan ekonomi.

Pada tahun 2008 PDRB Atas Dasar Harga Konstan Rp. 1.586.805,70 juta. Pada Tahun 2009 atas dasar harga konstan sebesar Rp 1.663.345,44 juta , pada tahun 2010 PDRB Atas Dasar Harga Konstan sebesar Rp. 5.665.580,12 juta. Tahun 2011 sebesar Rp. 5.999.303,26juta. Pada tahun 2012 PDRB Atas Dasar Harga Konstan sebesar Rp 6.365.857,71 juta . Pada tahun 2013 PDRB Atas Dasar Harga Konstan mencapai sebesar Rp 6.727.786,41 juta , pada tahun 2014 PDRB Atas Dasar Harga Konstan sebesar Rp 7.134.967,75 juta, pada tahun 2015 mencapai Rp. 7.576.313,96 juta, tahun 2016 PDRB Atas Dasar Harga Konstan Rp. 8.027.934,52 juta, dan pada tahun 2017 PDRB Atas Dasar Harga Konstan Rp. 8.454.052,24 juta (Sumber: PDRB berdasarkan harga konstan, BPS Kabupaten Jembrana)

Pertumbuhan ekonomi suatu daerah ditunjukkan dengan Laju Pertumbuhan PDRB suatu daerah.Walaupun PDRB Kabupaten Jembrana mengalami kenaikan akan tetapi presentase laju pertumbuhan ekonomi mengalami fluktuatif, Laju pertumbuhan PDRB Kabupaten Jembrana menurut lapangan usaha berdasarkan harga konstan yaitu pada tahun 2011 sebesar 5,89\%, tahun 2012 sebesar $6,11 \%$, tahun 2013 sebesar $5,69 \%$, dan pada tahun 2014 sebesar 6,05\%, pada tahun 2015 sebesar 6,19\%, pada tahun 2016 sebesar $5,96 \%$, dan pada tahun 2017 sebesar $5,31 \%$.

Berdasarkan data diatas maka ada sesuatu yang terjadi terhadap pertumbuhan ekonomi Kabupaten Jembrana walaupun
Jurnal Pendidikan Ekonomi Undiksha Volume 10 No. 2 Tahun 2018

pernyataan ini harus didukung dengan penelitian lebih mendalam, seperti apa sesungguhnya yang mendasari pertumbuhan ekonomi Kabupaten Jembrana, faktor apa yang paling dominan diantara faktor-faktor sumber pertumbuhan ekonomi tersebut, seperti sumberdaya alam, sumber daya manusia, pembentukan modal, dan teknologi. Hal tersebut menjadi alasan penulis untuk melakukan penelitian yang bertujuan untuk mengetahui faktor apa yang mempengaruhi pertumbuhan ekonomi di Kabupaten Jembrana tahun 2008-2017. Mengetahui Faktor mana yang paling dominan mempengaruhi pertumbuhan ekonomi di Kabupaten Jembrana tahun 2008-2017.

\section{METODE PENELITIAN}

Penelitian ini menggunakan rancangan penelitian faktorial, data dalam penelitian ini akan dianalisis dengan menggunakan analisis faktor, Menurut Sugiyono (2008) analisis faktor adalah suatu teknik yang digunakan untuk menganalisis tentang saling ketergantungan (interindependence) dari beberapa variabel secara simultan menjadi sejumlah faktor yang lebih sedikit dari variabel yang diteliti.Data penelitian adalah data kuantitatif, data kuantitaf adalah jenis data yang dapat diukur (measurable) atau dihitung sebagai variabel angka atau bilangan.Data kuantitatif ini diperoleh dari data PDRB (Produk Domestik Regional Bruto) Kabupaten Jembrana.Sumber data yang digunakan adalah data sekunder.Data sekunder merupakan sumber data yang diperoleh peneliti secara tidak langsung melalui media perantara.Data sekunder pada umumnya berupa bukti catatan, atau laporan historis yang telah tersusun dalam arsip, baik yang dipublikasikan dan yang tidak dipublikasikan.Data sekunder diperoleh dengan menggunakan metode dokumentasi dari Badan Perencanaan Pembangunan Daerah (BAPPEDA) Kabupaten Jembrana dan Badan Pusat Statistik (BPS) Kabupaten Jembrana.Menurut Sugiyono (2013) dokumen merupakan catatan peristiwa yang 
p-ISSN : 2599-1418

e-ISSN : 2599-1426

sudah berlalu.Dokumen bisa berbentuk tulisan, gambar, atau karya-karya monumental dari seorang.Data yang diperoleh kemudianakan dianalisis dengan analisis faktor melalui Statistical Program Social Scene (SPSS) 16.0 for window.Penelitian ini diharapkan menunjukan faktor-faktor apa saja yang mempengaruhi pertumbuhan ekonomi di Kabupaten Jembrana tahun 2008 sampai tahun 2017.

Menurut Arikunto (2007) Subyek penelitian merupakan sesuatu yang sangat penting kedudukanya di dalam penelitian, subjek penelitian harus ditata sebelum peneliti siap untuk mengumpulkan data.Subjek penelitian dapat berupa benda, hal atau orang.Pada penelitian ini yang menjadi subjek adalah instansi pemerintah Kabupaten Jembrana, yaitu BAPPEDA Kabupaten Jembrana dan BPS Kabupaten Jembrana. Sedangkan yang menjadi objek penelitian ini adalah PDRB berdasarkan haraga konstan, jumlah penduduk dan angkatan kerja Kabupaten Jembrana tahun 2008 sampai tahun 2017.

Jenis data yang digunakan dalam penelitian ini adalah data deskriptif kuantitatif berupa data dariBAPPEDA Kabupaten Jembrana dan BPS Kabupaten Jembrana berupa pertumbuhan ekonomi di Kabupaten Jembrana tahun2008-2017. Sedangkan, Data sekunder yaitu data yang diperoleh dari sumber-sumber yang dianggap perlu yang ada hubungannya dengan penelitian berupa data Produk Domestik Regional Bruto (PDRB) berdasarkan harga konstan dari BAPPEDA Kabupatan Jembrana dan BPS Kabupatan Jembrana.

Teknik pengumpulan data yang digunakan dalam penelitian ini adalah metode dokumentasi.Metode dokumentasi menurut Arikunto (2007) yaitu mencari data mengenai variabel yang berupa catatan, transkip, buku, surat kabar, majalah, prasasti, notulen rapat, agenda dan sebagainya.Data yang diperoleh dari metode dokumentasi adalah data berupa PDRB berdasarkan harga konstan, yang diperoleh dari BPS Kabupaten Jembrana
Jurnal Pendidikan Ekonomi Undiksha

Volume 10 No. 2 Tahun 2018

dan jumlah penduduk serta angkatan kerja yang sudah dibukukan kedalam Jembrana dalam angka dari BAPPEDA Kabupaten Jembrana tahun 2008 sampai tahun 2017.

Teknik analisis data dalam penelitian ini menggunakan analisis faktor dengan tahap-tahap sebagai berikut;1) Membuat matrik.Matrik korelasi dapat diidentifikasikan variabel-variabel tertentu yang tidak mempunyai korelasi dengan variabel yang lain, sehingga dapat dikeluarkan dari analisis. Untuk menguji ketepatan model analisis faktor, maka dapat digunakan Barlett's test of Sphericity yang dipakai untuk menguji bahwa variabel-variabel dalam sampel berkorelasi ataupun tidak berkorelasi.Hasil Barlett's test of Sphericity menunjukkan apakah hubungan antara variabel-variabel signifikan atau tidak. Statistik lain yang berguna adalah pengukuran kelayakan sampel Kaiser Meyer Olkin (KMO). Analisis faktor dianggap layak untuk dianalisis lebih lanjut jika besaran KMO nilainya minimal 0,50. Besaran ini digunakan untuk mengukur derajat korelasi antar variabel dengan kriteria Measure of Sampling Adequacy (MSA) $\geq 0,5 ; 2$ ) Menentukan jumlah faktor,variabel disusun kembali berdasarkan pada korelasi hasil langkah pada butir dua untuk menentukan faktor yang diperlukan mewakili data.Untuk menentukan berapa faktor yang diterima secara empirik dapat dilakukan berdasarkan besarnya eigenvalue setiap faktor yang muncul.Semakin besar eigenvalue setiap faktor, semakin representatif faktor tersebut untuk mewakili sekelompok variabel. Faktor-faktor yang dipilih adalah faktor yang mempunyaieigenvalue sama dengan atau lebih dari 1. Jika eigenvalue kurang dari 1 , maka faktor tersebut tidak bisa diterima untuk mewakili data yang diteliti; 3) Rotasi faktor,apabila hasil penyederhanaan faktor dalam matrik faktor memperlihatkan hubungan antara faktor dengan variabel individu, tetapi dalam faktor-faktor tersebut terdapat banyak variabel yang berkorelasi sehingga sulit diinterpretasikan.Dengan menggunakan rotasi faktor matrik, matrik faktor ditranspormasikan ke dalam matrik 
p-ISSN : 2599-1418

e-ISSN : 2599-1426

yang lebih sederhana sehingga mudah untuk diinterpretasikan.Dalam perilaku ini digunakan rotasi varimax; 4) Interpretasi faktor,interpretasi faktor dilakukan dengan mengelompokkan variabel yang mempunyai faktor loading tinggi ke dalam faktor tersebut. Untuk menginterpretasikan hasil penelitian ini, faktor loading minimal 0,5. Variabel yang mempunyai faktor loading kurang dari 0,5 dikeluarkan dari model; 5) Menentukan ketepatan model, tahap terakhir dari analisis faktor adalah mengetahui apakah model mampu menjelaskan dengan baik fenomena yang ada perlu diuji dengan teknik Principal Component Analisis (PCA) yaitu dengan melihat jumlah resudial antara korelasi yang diamati dengan korelasi yang direproduksi. Dalam penelitian ini, untuk mempermudah proses perhitungan dan untuk mendapatkan hasil perhitungan yang akurat dalam analisis data, peneliti menggunakan bantuan program SPSS 16.0 for Windows.

\section{HASIL DAN PEMBAHASAN}

Jurnal Pendidikan Ekonomi Undiksha Volume 10 No. 2 Tahun 2018
Berdasarkan tujuan dalam penelitian ini yaitu untuk mengetahui faktor-faktor yang mempengaruhi serta faktor mana paling dominan yang mempengaruhi pertumbuhan ekonomi di Kabupaten Jembrana tahun 2008 sampai dengan tahun 2017, maka dilakukan analisis menggunakan analisis faktor dengan bantuan program SPSS for Windows versi 16.0. Analisis faktor digunakan untuk menguji hipotesis dengan memasukkan semua total nilai dari masing-masing dimensi atau faktor terhadap total skor item dari masing-masing dimensi, kemudian dilakukan penentuan matrik korelasi penentuan jumlah faktor, membuat rotasi faktor, dan menentukan skor masingmasing faktor.

Untuk mengukur kecukupan sample dalam penelitian ini digunakan Koefisien Kaiser-Mayer-Olkin (KMO) and Barlett's Test of Sphericitydengan syarat jika nilai KMO > 0,5 dan uji Bartlett's Test of Sphericity apabila nilai signifikan $<0,05$ Adapun hasil uji KMO dan Bartlett's Test of Sphericitydapat dilihat pada Tabel 1.

Tabel 1.Hasil untuk Penelitian KMO and Barlett's Test of Sphericity

KMO and Bartlett's Test

Kaiser-Meyer-Olkin Measure of Sampling

Adequacy.

.616

\begin{tabular}{llr}
\hline Bartlett's Test of & Approx. Chi-Square & 182.113 \\
Sphericity & Df & 28 \\
& Sig. & .000 \\
\hline
\end{tabular}

Berdasarkan hasil analisis faktor diperoleh nilai KMO sebesar 0,616. Dengan demikian angka KMO Measure of Sampling Adequency lebih besar dari 0,5 . Hal ini berarti bahwa jumlah sampel yang digunakan dalam penelitian ini sudah cukup memenuhi syarat dan analisis faktor tepat digunakan untuk menganalisis data yang diperoleh.Hasil pengujian Barlett's Test of Sphericity menunjukkan hasil penelitian yang signifikan pada taraf nyata 0,000 . Hal ini berarti matrik korelasi memiliki korelasi yang signifikan dengan sejumlah variabel, karena nilai signifikan lebih kecil dari $\alpha=$ 0,05 .

Pada hasil output Statistical Package for the Social Sciences (SPSS) 16.0 for Windows (Anti-image Matrics), dapat diketahui faktor-faktor atau variabel-variabel yang layak digunakan dalam analisis faktor. Hasil output SPSS (Anti-image Matrics), terdapat kode "a"yang artinya tanda untuk 
p-ISSN : 2599-1418

e-ISSN : 2599-1426

Measure of Sampling Adequency (MSA), faktor atau variabel yang layak digunakan dalam analisis adalah variabel yang memiliki nilai $M S A>0,50$. Apabila terdapat variabel yang memiliki nilai $M S A<0,50$,
Jurnal Pendidikan Ekonomi Undiksha Volume 10 No. 2 Tahun 2018

maka variabel tersebut dikeluarkan agar dapat dilakukan analisis faktor. Nilai MSA masing-masing variabel dapat dilihat pada Tabel

Tabel 2.Nilai MSA Variabel

\begin{tabular}{|c|c|c|}
\hline Variabel & Nilai MSA & Keputusan \\
\hline Sumberdaya alam & $0,871>0,50$ & Dapat digunakan untuk analisis faktc \\
\hline modal & 96 & $\mathrm{k}$ analisis faktor \\
\hline & 0 & tuk analisis faktor \\
\hline n teknologi & 0,06 & lisis faktor \\
\hline $\begin{array}{l}\text { Pembagian kerja dan } \\
\text { skala produksi }\end{array}$ & 0,62 & gunakan untuk analisis faktor \\
\hline Fakto & 0,6 & Dapat dig \\
\hline Fak & & $\begin{array}{l}\text { Tidak dapat digunakan untuk analisis } \\
\text { faktor }\end{array}$ \\
\hline $\begin{array}{l}\text { Faktor politik } \\
\text { administrative }\end{array}$ & $0,588>0,50$ & Dapat digunakan untuk \\
\hline
\end{tabular}

Berdasarkan tabel 4.2 tersebut di atas, terdapat satu variabel yang tidak dapat digunakan untuk analisi faktor yaitu faktor manusia.Pada dasarnya pertumbuhan ekonomi tidak semata-mata tergantung pada jumlah sumberdaya manusia saja, tetapi lebih menekankan pada efesiensi mereka. Maka penelitian harus diulangi tanpa mengikut sertakan faktor manusia untuk menentukan $\mathrm{KMO}$ and Barlett's Test of Sphericity dan nilai MSA, dapat dilihat pada tabel 3 dan table 4

\section{Tabel 3.Hasil untuk Penelitian KMO and Barlett's Test of Sphericity}

KMO and Bartlett's Test

\begin{tabular}{llr} 
Kaiser-Meyer-Olkin Measure of Sampling & .777 \\
\hline Adequacy. & & 183.864 \\
\hline Bartlett's Test of & Approx. Chi-Square & 21 \\
Sphericity & Df & .000 \\
& Sig. & \\
\hline
\end{tabular}

Berdasarkan hasil analisis faktor diperoleh nilai KMO sebesar 0,777. Dengan demikian angka KMO Measure of Sampling Adequency lebih besar dari 0,5. Hal ini berarti bahwa jumlah sampel yang digunakan dalam penelitian ini sudah cukup memenuhi syarat dan analisis faktor tepat digunakan untuk menganalisis data yang diperoleh. Hasil pengujian Barlett's Test of Sphericity menunjukkan hasil penelitian yang signifikan pada taraf nyata 0,000 . Hal ini berarti matrik korelasi memiliki korelasi yang signifikan dengan sejumlah variabel, karena nilai signifikan lebih kecil dari $\alpha=$ 0,05 . 
Tabel 4.Nilai MSA Variabel

\begin{tabular}{|c|c|c|}
\hline Variabel & Nilai MSA & Keputusan \\
\hline Sumberdaya alam & $0,788>0,50$ & Dapat digunakan untuk analisis faktor \\
\hline lasi modal & $0,781>0$ & nalisis faktor \\
\hline Organisasi & $0,726>0,50$ & Dapat digunakan untuk analisis faktor \\
\hline Kemajuan teknologi & 0,78 & gunakan untuk analisis faktor \\
\hline $\begin{array}{l}\text { Pembagian kerja dan } \\
\text { skala produksi }\end{array}$ & 0,80 & Dapat digunakan untuk analisis faktor \\
\hline Faktor sosial & & aktor \\
\hline $\begin{array}{l}\text { Faktor politik } \\
\text { administratif }\end{array}$ & 0,8 & tuk analisis faktor \\
\hline
\end{tabular}

Berdasarkan Tabel 4 tersebut di atas, maka dapat diketahui faktor-faktor yang digunakan dalam analisis faktor. Faktor tersebut yaitu; sumberdaya alam, akumulasi modal, organisasi, kemajuan teknologi, pembagian kerja dan skala produksi, faktor sosial, faktor politik dan administratif.

Untuk menentukan jumlah faktor baru yang dapat terbentuk dalam faktor- faktor yang mempegaruhi pertumbuhan ekonomi di Kabupaten Jembrana tahun 2008 sampai dengan tahun 2017, dapat dijelaskan oleh Nilai Total Variance Explained digunakan untuk mengetahui persentase dari ketujuh faktor yang dianalisis.dapat dilihat pada Tabel 5

Tabel 5.Total Variance Explained

\begin{tabular}{|c|c|c|c|c|c|c|}
\hline \multicolumn{7}{|c|}{ Total Variance Explained } \\
\hline \multirow{2}{*}{ Component } & \multicolumn{3}{|c|}{ Initial Eigenvalues } & \multicolumn{3}{|c|}{$\begin{array}{l}\text { Extraction Sums of Squared } \\
\text { Loadings }\end{array}$} \\
\hline & Total & $\begin{array}{c}\text { \% of } \\
\text { Variance }\end{array}$ & $\begin{array}{l}\text { Cumulativ } \\
\mathrm{e} \%\end{array}$ & Total & $\begin{array}{c}\% \text { of } \\
\text { Variance }\end{array}$ & $\begin{array}{c}\text { Cumulativ } \\
\mathrm{e} \%\end{array}$ \\
\hline $\begin{array}{l}\text { Sumberdaya } \\
\text { alam }\end{array}$ & 6.765 & 96.649 & 96.649 & 6.765 & 96.649 & 96.649 \\
\hline $\begin{array}{l}\text { Akumulasi } \\
\text { modal }\end{array}$ & .209 & 2.989 & 99.637 & & & \\
\hline Organisasi & .018 & .262 & 99.899 & & & \\
\hline $\begin{array}{l}\text { Kemajuan } \\
\text { teknologi }\end{array}$ & .004 & .051 & 99.950 & & & \\
\hline $\begin{array}{l}\text { Pembagian } \\
\text { kerja dan skala } \\
\text { produksi }\end{array}$ & .003 & .042 & 99.992 & & & \\
\hline Faktor sosial & .000 & .006 & 99.997 & & & \\
\hline $\begin{array}{l}\text { Faktor politik } \\
\text { dan administratif }\end{array}$ & .000 & .003 & 100.000 & & & \\
\hline
\end{tabular}


p-ISSN : 2599-1418

e-ISSN : 2599-1426

Dari Tabel 5, dapat diketahui persentase dari masing-masing faktor antara lain: faktor sumberdaya alam memiliki eigenvalue sebesar 6,765 dengan nilai varian sebesar $96.649 \%$, faktor akumulasi modal memiliki eigenvaluesebesar 0,209 dengan nilai varian sebesar $2,989 \%$, faktor organisasi memiliki eigenvaluesebesar 0,018 dengan nilai variance sebesar $0,262 \%$, faktor kemajuan teknologi memiliki eigenvaluesebesar 0,004 dengan nilai varian sebesar $0,051 \%$, faktor pembagian kerja dan skala produksi memiliki eigenvaluesebesar 0,003 dengan nilai variance sebesar $0,042 \%$, faktor sosial memiliki eigenvaluesebesar 0,000 dengan nilai variance sebesar $0,006 \%$ dan faktor politik dan administratif memiliki eigenvalue sebesar 0,000 dengan nilai varian sebesar $0,003 \%$. Menurut Yamin dan Kurniawan (2009) total variance explained menerangkan nilai persen dari varians yang mampu diterangkan oleh banyaknya faktor yang terbentuk. Dari ketujuh faktortersebut hanya satu faktor yang memiliki
Jurnal Pendidikan Ekonomi Undiksha Volume 10 No. 2 Tahun 2018

eigenvalue $>1$ yaitu faktor sumberdaya alam sebesar 6,765 total nilaivariance explained dari faktor sumberdaya alam adalah 96,649\%.dengan kata lain faktor sumberdaya alam mampu menjelaskan pengaruhnya sebesar 96,649\% terhadap pertumbuhan ekonomi di Kabupaten Jembrana tahun 2008 sampai dengan tahun 2017.

Untuk mengetahui korelasi antara faktor independen dengan faktor baru yang terbentuk dilakukan interprestasi faktor dengan mengelompokkan faktor yang mempunyai faktor loading tinggi ke dalam faktor tersebut. Untuk menginterperstasikan hasil penelitian ini dapat dilihat pada output SPSS 16.0 (Component Matrix). Faktor loading minimal 0,5 , jika faktor yang mempunyai faktor loading kurang dari 0,5 dikeluarkan dari faktor baru yang terbentuk faktor yang termasuk kedalam faktor loading mampu menjelaskan pertumbuhan ekonomi di Kabupaten Jembrana tahun 2008 sampai dengan 2017, dapat dilihat pada Tabel 6.

\section{Tabel 6.Faktor-Faktor yang Mempengaruhi Pertumbuhan Ekonomi di Kabupaten} Jembrana tahun 2008 sampai dengan tahun 2017

\begin{tabular}{lccc}
\hline Faktor & Eigenvalue & $\begin{array}{c}\text { Variance } \\
\text { Explained (\%) }\end{array}$ & Faktor Loading \\
\cline { 3 - 4 } Sumberdaya alam & 6,765 & 96,649 & 0,970 \\
Akumulasi modal & 0,209 & 2,989 & 0,999 \\
Organisasi & 0.018 & 0,262 & 0,998 \\
Kemajuan teknologi & 0,004 & 0,051 & 0,993 \\
Pembagian kerja dan & 0,003 & 0,042 & 0,999 \\
skala produksi & & & 0,998 \\
Faktor sosial & 0,000 & 0,006 & 0,924 \\
Faktor politik dan & 0,000 & 0,003 &
\end{tabular}
administratif

$\begin{array}{llll}\begin{array}{c}\text { Berdasarkan Tabel 6, dapat } \\ \text { dijelaskan bahwa korelasi faktor }\end{array} & & \begin{array}{l}\text { faktor politik dan administratif. Kelompok } \\ \text { faktor tersebut memiliki korelasi yaitu faktor }\end{array} \\ \text { independen dengan faktor yang hendak } & \text { pembagian kerja dan skala produksi } \\ \text { terbentuk, karena hanya ada satu faktor } & \text { sebesar 0,999, akumulasi modal sebesar } \\ \text { yang memiliki Eigenvalue >1 maka, hanya } & 0,999 \text {, organisasi sebesar 0,998, faktor } \\ \text { satu faktor baru yang terbentukdari faktor } & \text { sosial sebesar 0,998, kemajuan teknologi } \\ \text { sumberdaya alam, akumulasi modal, } & \text { sebesar 0,993, sumberdaya alam sebesar } \\ \text { organisasi, kemajuan teknologi, pembagian } & 0,970, \text { dan faktor politik dan administratif } \\ \text { kerja dan skala produksi, faktor sosial, dan } & \text { sebesar } & \end{array}$


p-ISSN : 2599-1418

e-ISSN : 2599-1426

Hasil penelitian yang berdasarkan pengujian hipotesis, untuk menentukan dimensi atau faktor dalam pertumbuhan ekonomi di Kabupaten Jembrana yang paling dominan digunakan parameter koefisien varimax atau mendekati nilai -1 .
Jurnal Pendidikan Ekonomi Undiksha Volume 10 No. 2 Tahun 2018

Tabel 7.Matriks Rotasi Hasil Analisis Faktor

Dimensi atau faktor pertumbuhan ekonomi

Varimax Rotation (\%)

Nilai yang mendekati 1 diawali oleh nilai 0,5 sedangkan nilai yang mendekati -1 diawali oleh $-0,5$. Secara lebih rinci hasil ringkasan rotasi dan matriks faktor memuat nilai varimax rotation, dapat dilihat pada Tabel 7

(1)

96,649
(2)

sebesar $0,006 \%$, serta faktor politik dan administratif sebesar $0,003 \%$.

Ketujuh faktor tersebut yang mempengaruhi pertumbuhan ekonomi di Kabupaten Jembran tahun 2008 sampai dengan tahun 2017 tidak sesuai dengan teori yang dinyatakan oleh M.L.Jhingan (2012 : 67), bahwa ada delapan faktor sebagai sumber pertumbuhan ekonomi yaitu (1) sumberdaya alam, (2) akumulasi modal, (3) organisasi, (4) kemajuan teknologi, (5) pembagian kerja dan skala produksi, (6) faktor sosial, (7) faktor manusia, dan (8) faktor politik dan administratif, karena faktor manusia tidak sesuai untuk mengukur pertumbuhan ekonomi di Kabupaten Jembrana. Dari tujuh faktor tersebut, yang paling dominan mempengaruhi pertumbuhan ekonomi di Kabupaten Jembran tahun 2008 sampai dengan tahun 2017 adalah faktor sumbeerdaya alam yang mempunyai nilai variance sebesar $96,649 \%$. Seperti yang kita ketahui bahwa sumberdaya alam merupakan kemampuan yang dimiliki daerah yang dikelola untuk mendapatakan hasil bumi. Pertanian, kehutanan, perikanan, pertambangan dan penggalian yang dikelola denan baik dan efesien akan mampu mengantarkan pada meningkatnya pertumbuhan ekonomi. Pemberdayaan sumberdaya alam yang dimiliki oleh Kabupaten Jembrana tentunya melalui proses yang efektif dan efesien. Pendapatan hasil bumi merupakan gambaran dari bagaimana pemanfaatan dari sumberdaya alam yang dimiliki oleh Kabupaten Jembrana, sehingga 
p-ISSN : 2599-1418

e-ISSN : 2599-1426

pendapatan dari hasil bumi mampu menentukan pertumbuhan ekonomi di Kabupaten Jembrana.

\section{SIMPULAN DAN SARAN}

Bedasarkan hasil penelitian dan pembahasan, maka dapat disimpulkan sebagai berikut.Faktor-faktor yang mempengaruhi pertumbuhan ekonomi di Kabupaten Jembrana tahun 2008-2017 adalah sumberdaya alam dengan nilai varian sebesar $96,649 \%$, akumulasi modal dengan nilai varain sebesar 2,989\%, organisasi dengan nilai varian sebesar $0,262 \%$, kemajuan teknologi dengan nilai varian sebesar $0,051 \%$, pembagian kerja dan skala produksi dengan nilai varian sebesar $0,042 \%$, faktor sosial dengan nilai varian sebesar $0,006 \%$, serta faktor politik dan administratif dengan varain sebesar $0,003 \%$.Faktor yang paling dominan mempengaruhi pertumbuhan ekonomi di Kabupaten Jembrana tahun 2008-2017 adalah faktor sumberdaya alam dengan nilai varimax rotation $96,649 \%$

Berdasarkan pembahasan dan simpulan di atas, maka dapat diajukan beberapa saran sebagai berikut.Bagi pihak pemerintah Kabupaten Jembrana, dalam upaya peningkatan pertumbuhan ekonomi di daerah harus lebih mengoptimalkan potensi faktor-faktor yang ada dalam pertumbuhan ekonomi di Kabupaten Jembrana.Dalam mengoptimalkan. Bagi masyarakat Kabupaten Jembrana, untuk lebih merangsang diri agar lebih mengoptimalkan sumberdaya alam yang ada di daerah daripada merantau keluar daerah .Bagi peneliti lain yang berminat untuk meneliti pertumbuhan ekonomi disarankan untuk mengembangkan penelitian ini dengan mengembangkan metode yang sama pada Kabupaten/Kota
Jurnal Pendidikan Ekonomi Undiksha Volume 10 No. 2 Tahun 2018

yang berbeda. Hal ini berguna untuk menguji keberlakuan temuan faktor-faktor yang mempengaruhi pertumbuhan ekonomi agar hasilnya lebih maksimal.

\section{DAFTAR PUSTAKA}

Arikunto, S. 2007. Prosedur Penelitian Suatu Pendekatan Praktek Edisi, Rineka Apta, Jakarta

Badan Pusat Statistik. 2008-2017. PDRB Menurut Lapangan Usaha Berdasarkan Harga Konstan. Jembrana: BPS

Jhingan, M.L. 2012, Ekonomi Pembangunan dan Perencanaan. (Alih Bahasa: D.Guritno). Jakarta: Rajawali Pers

Sugiyono, 2008. Metode Penelitian Bisnis.Cetakan.Bandung : Alfabeta

Sugiyono. 2013. Metode Penelitian Kuantitatif Kualitatif dan R\&D. Bandung: Alfabeta

Sukirno, S. 2008. Mikroekonomi: Teori Pengantar. Edisi Ketiga. Jakarta: PT Raja Grafindo Persada

Sukirno, S. 2011, Makro Ekonomi Teori Pengantar Edisi Ketiga. Rajawali Pers, Jakarta

Suliyanto.2005. Analisis Data Dalam Aplikasi Pemasaran.Bogor: Galia Indonesia.

Supranto, J. 2010. Statistika. Jakarta: Erlangga.

Yamin, S \& Kurniawan.2009.SPSS Complete. Teknik Analisis Statistik Terlengkap dengan Software SPSS. Jakarta: Selembar Infote 